\title{
Mid-term clinical and radiographic outcomes of porous-coated metaphyseal sleeves used in revision total knee arthroplasty
}

Ron Gurel ${ }^{1^{*}}$ D, Samuel Morgan², Etay Elbaz ${ }^{1}$, Itay Ashlenazi ${ }^{1}$, Nimrod Snir ${ }^{1}$, Assaf Kadar ${ }^{1}$, Aviram Gold ${ }^{1}$ and Yaniv Warschawski ${ }^{1}$

\begin{abstract}
Background: The management of bone defects remains one of the major challenges surgeons are faced with in revision total knee arthroplasty (RTKA). Large and uncontained bone defects are traditionally managed with metaphyseal sleeves that facilitate osseointegration and have reported construct stability. While many studies have presented excellent short-term outcomes using metaphyseal sleeves, less is known on their performance in the longer term. The purpose of this study was to present our mid-term results of the metaphyseal sleeves used in patients undergoing RTKA.
\end{abstract}

Materials and methods: Between January 2007 and January 2015, 30 patients underwent RTKA with the use of a CCKMB prosthesis combined with an osteointegrative sleeve. The main indications for RTKA were instability in $40 \%$ of the cases ( $n=12)$, aseptic loosening in 30\% ( $n=9)$, infection in 26.7\% $(n=8)$, and "other" in 3.3\% $(n=1)$. The minimal follow-up time was 5 years and the mean follow-up time was 82.4 months ( $S D=22.6)$. Clinical outcomes were assessed by Knee Society scores (KSS), range of motion and rate of re-operation.

Results: The mean Knee Society score increased significantly from 72.1 preoperatively to 90.0 postoperatively $(p<$ 0.001). The cumulative incidence of re-operation in our study was $13.3 \%(n=4)$. Our study reported no cases of aseptic loosening or mobile-bearing spin-out. Knee flexion to $90^{\circ}$ and more was impossible in seven cases (23.3\%) preoperatively and in one case (3.3\%) postoperatively.

Conclusion: Porous-coated metaphyseal sleeves demonstrated excellent rates of survivorship and radiographic ingrowth in the mid-term setting. However, further studies are required to assess their outcomes in the long-term.

Keywords: Revision total knee arthroplasty, Metaphyseal sleeve, Bone loss

\footnotetext{
* Correspondence: rongurel@gmail.com

'Orthopedic Department, affiliated to the Sackler Faculty of Medicine, Tel

Aviv Sourasky Medical Center, Ichilov Hospital, Tel Aviv University, 6 Weizman St, 6423906 Tel Aviv, Israel

Full list of author information is available at the end of the article
}

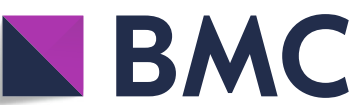

Part of Springer Nature
(9) The Author(s). 2021 Open Access This article is licensed under a Creative Commons Attribution 4.0 International License, which permits use, sharing, adaptation, distribution and reproduction in any medium or format, as long as you give appropriate credit to the original author(s) and the source, provide a link to the Creative Commons licence, and indicate if changes were made. The images or other third party material in this article are included in the article's Creative Commons licence, unless indicated otherwise in a credit line to the material. If material is not included in the article's Creative Commons licence and your intended use is not permitted by statutory regulation or exceeds the permitted use, you will need to obtain permission directly from the copyright holder. To view a copy of this licence, visit http://creativecommons.org/licenses/by/4.0/ The Creative Commons Public Domain Dedication waiver (http://creativecommons.org/publicdomain/zero/1.0/) applies to the data made available in this article, unless otherwise stated in a credit line to the data. 


\section{Introduction}

The number of revision total knee arthroplasty (RTKA) procedures performed worldwide is increasing, along with the increasing life expectancy [1-3]. The management of bone loss in the femoral and the tibial articular surfaces remains one of the major challenges that surgeons are faced with during RTKA. Metaphyseal bone loss can compromise fixation of components and can lead to component malalignment due to the loss of normal anatomic landmarks [4].

Large and uncontained bone defects are traditionally best managed with structural allografts or metal filling devices such as cones and sleeves [5]. The use of structural allografts has had reported complications of instability, fracture of the graft, as well as reported transmission of infection [6]. Metaphyseal implants therefore represent a promising alternative to address bone loss. While the literature on cones has demonstrated good mid-term outcomes [7-9], their downside involves reported fractures of the host bone, extraction difficulty, and the fact that they may require additional bone grafting $[5,6]$.

The use of metaphyseal sleeves has gained popularity in recent years due to their purported benefits of construct stability. By facilitating osseointegration, filling bone defects and providing a stable scaffold for knee reconstruction, these sleeves may improve long-term implant survival rate [10]. They are thought to offer advantages over the conventional trabecular cones including optimization of the bone-implant interface and the fact that they add rotational stability, especially in cases of femoral defects with posterior bone loss [11]. While previous studies have demonstrated reliable fixation using sleeves [12-14], these were only evaluated in a short-term setting ( $<5$-year follow-up).

The literature on the outcomes of metaphyseal sleeves in the mid-term is limited $[11,15,16]$ and more evidence is required in order to make definitive clinical decisions. The purpose of our study was to present our mid-term results of metaphyseal sleeves used in patients undergoing RTKA. We hypothesized that that metaphyseal sleeves offer good solution to bone defects encountered during RTKA and have good mid-term survivorship.

\section{Materials and methods}

Institutional Research Ethics Board approval was obtained for this retrospective study (reference no: 061419-TLV). A search of our institutional research database was performed to identify patients having undergone revision TKA with a specific CCKMB prosthesis (Press-Fit Condylar Sigma Total Condylar 3 Rotating-Platform; DePuy, Warsaw, IN, USA) between January 2008 and January 2018. Only cases with a minimum of 5 years of follow-up and where an osteointegrative sleeve component was used were included. Data was gathered from the patients' electronic medical records and included baseline patient characteristics such as gender, age, body mass index (BMI), the use of stem and sleeve components, stem sizes, and the indication for using a constrained implant. The indications for using a constrained implant included instability, aseptic loosening, infection or periprosthetic fracture. Data regarding complications was additionally collected.

All patients were followed at routine postoperative visits at 6 weeks, 3 months, 6 months, 1 year and yearly thereafter. Clinical outcomes were assessed by Knee Society Scores (KSS) [17] and range of motion (ROM). Preoperative and postoperative radiographs, including anterior-posterior, lateral and sky views of the knee, were routinely obtained during follow-up visits in order to evaluate bone defects based on the Anderson Orthopedic Research Institute (AORI) classification. The AORI system classifies femoral and tibial defects separately into types I, II, and III. In type-I defects, the metaphyseal bone is intact, with minor bone defects not compromising component stability. In type-II defects, there is metaphyseal bone damage and cancellous bone loss in one femoral/tibial condyle (type IIA) or both femoral/tibial condyles (type IIB); cement reinforcement, bone grafting or metal augmentation is needed. In typeIII defects, the metaphyseal bone is deficient and a structural allograft or a custom-made, hinged or revision prosthesis with an extended intramedullary stem is needed [18]. The radiographs were further evaluated for radiolucent lines graded with the Knee Society rating system [19] and signs of aseptic loosening such as radiolucent lines around the whole implant, implant migration $>2 \mathrm{~mm}$, or cement/implant fracture (Fig 1). Clinical outcomes were assessed by KSS [17], ROM, and documentation of the complications.

Statistical analysis included mean and standard deviation (SD) for continuous variables and percentages and chi square for categorical variables. The $T$ test was used to compare mean preoperative to postoperative KSS. Cumulative incidence of re-revision was calculated and presented in Table 5 with descriptions of the causes of re-revisions. Statistical significance was set at a $P$ value $<0.05$. All analyses were conducted using SPSS software, version 24 (IBM, Armonk, NY, USA).

\section{Results}

Between January 2007 to January 2015, 30 patients underwent RTKA with the use of the CCKMB prosthesis combined with an osteointegrative sleeve. The main indications for RTKA were instability in $40 \%$ of the cases $(n=12)$, aseptic loosening in $30 \%(n=30)$, infection in $26.7 \%(n=8)$, and periprosthetic fracture in $3.3 \%(n=1)$ 


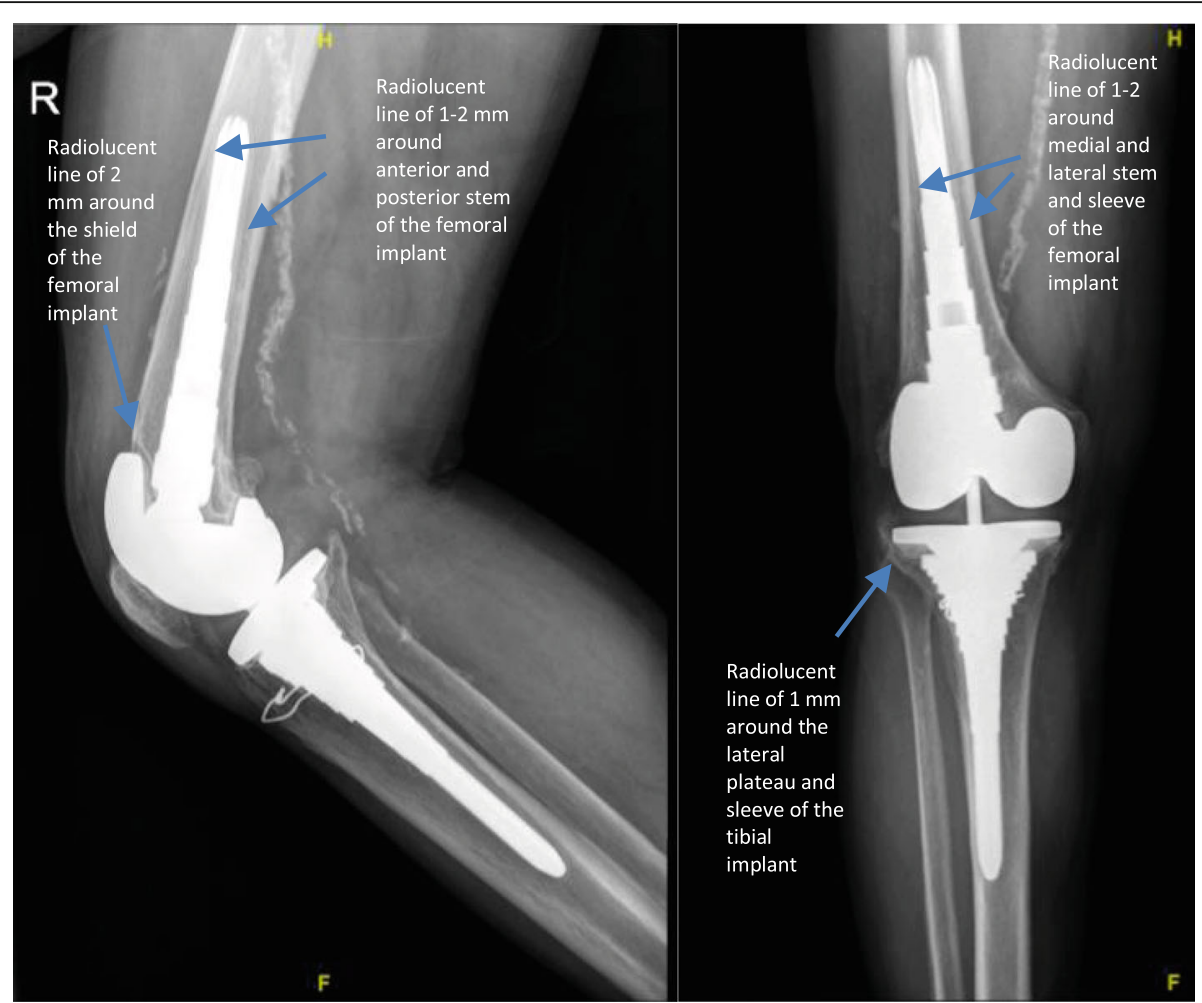

Fig. 1 Antero-posterior (AP) and lateral view of the right knee of a 68-year old patient who underwent a second-stage revision total knee arthroplasty. A non-progressive radiolucent line of 1-2 $\mathrm{mm}$ around the stem, the anterior part of the femoral sleeve and the tibial plate are seen in radiographs taken 7 years postoperatively. Clinically, the patient had no signs of loosening

(Table 1). Table 2 describes the characteristics of the study population. Out of 30 cases, 20 (66.7\%) were women and $15(50 \%)$ were left knee procedures. The mean BMI was $30.2 \mathrm{~kg} / \mathrm{m} 2 \quad(\mathrm{SD}=5.2)$. The minimal follow-up time was 5 years and the mean follow-up time was 82.5 months $(S D=22.6)$. Three patients were lost to follow-up. Tables 3 and 4 present the distribution of stems and metaphyseal sleeves use in the femoral and tibial implants of the study population. In $90 \%(n=27)$ of the cases a stem was used in both the femoral and the tibial implants and in $70 \%(n=21)$ of the cases a metaphyseal sleeve was used in both the femoral and the tibial implants. See Tables 3 and-4 for the full description.

\section{Knee Society Score before and after RTKA}

Average preoperative and postoperative KSS (Table 5) of our cohort was $72.1(\mathrm{SD}=17.3)$ and $90.0(\mathrm{SD}=13.9)$,

Table 1 Indications for revision total knee arthroplasty (TKA)

\begin{tabular}{lll}
\hline Indication & N & (\%) \\
\hline Instability & 12 & 40.0 \\
Aseptic loosening & 9 & 30.0 \\
Infection & 8 & 26.7 \\
Periprosthetic fracture & 1 & 3.3 \\
\hline
\end{tabular}

respectively. Mean difference before and after the operation showed a mean increase of 17.9 points in the score and paired sample $T$ test comparing the scores showed this difference was statistically significant $(95 \%$ CI 8.0-27.8, $P$ value $<0.001$ ).

Table 2 Study population

\begin{tabular}{ll}
\hline Age (years) & $69.9(7.0)$ \\
Mean (SD) & \\
Gender, $n(\%)$ & $10(66.7 \%)$ \\
Female & $10(33.3 \%)$ \\
Male & $15(50 \%)$ \\
Side $n(\%)$ & $15(50 \%)$ \\
Left & \\
Right & $30.2(5.2)$ \\
BMI (kg/m $\left.{ }^{2}\right)$ & \\
Mean (SD) & $82.5(22.6)$ \\
Follow-up period (months) & \\
Mean (SD) & $14(46.7 \%) / 9(30.3 \%) / 7(23.3 \%) / 0$ \\
Bone defects, $n$ (\%) & $28(93.3 \%) / 2(6.7 \%) / 0 / 0$ \\
Tibia I/lla/llb/III & \\
Femur l/lla/Ilb/III &
\end{tabular}


Table 3 Stem and sleeve use distribution

\begin{tabular}{llll}
\hline & & $\boldsymbol{n}$ & $\%$ \\
\hline Stem & Femoral only & 2 & 6.7 \\
& Tibial only & 1 & 3.3 \\
Sleeve & Both components & 27 & 90.0 \\
& Femoral only & 4 & 13.3 \\
& Tibial only & 5 & 16.7 \\
& Both components & 21 & 70.0 \\
\hline
\end{tabular}

\section{Ranges of motion before and after RTKA}

Preoperatively, seven cases (23.3\%) experienced flexion contracture, and postoperatively, the number of cases with flexion contracture decreased to four (13.3\%). Knee flexion to $90^{\circ}$ and more was impossible in seven cases (23.3\%) before RTKA and in one case (3.3\%) after RTKA. The mean flexion and extension limits preoperatively were $101.1^{\circ}$ $(\mathrm{SD}=19.0)$ and $1.8^{\circ}(\mathrm{SD}=3.3)$, respectively. The mean flexion and extension limits postoperatively were $104.6^{\circ}$ $(\mathrm{SD}=13.6)$ and $1.5^{\circ}(\mathrm{SD}=4.3)$, respectively.

\section{Radiographic evaluation}

Postoperative anteroposterior and lateral radiographs were assessed for radiolucent lines around the femoral and tibial components and the findings are described in Table 6. There were no signs of aseptic loosening in the radiographs of the cohort population.

\section{Re-operation following RTKA with CCKMB implant}

Table 7 describes the re-revisions including details regarding the etiology and time of re-revision. Rerevision was required in four patients $(13.3 \%)$ during the follow-up period. Two of the re-operations were early, as they occurred at 0.3 and 0.7 months after RTKA. One patient was surgically treated for a tibial-tuberosity avulsion fracture at 0.7 months and there was another case of drainage of subcutaneous hematoma at 0.3 months after RTKA. Two re-revisions were late and occurred at

Table 4 Stem sizes

\begin{tabular}{llll}
\hline Tibia $(n=27)$ & Length $n(\%)$ & $75 \mathrm{~mm}$ & $22(81.5 \%)$ \\
& & $115 \mathrm{~mm}$ & $5(18.5 \%)$ \\
& Diameter $n(\%)$ & $10 \mathrm{~mm}$ & $6(22.2 \%)$ \\
& & $12 \mathrm{~mm}$ & $10(37.0 \%)$ \\
Femur $(n=28)$ & $14 \mathrm{~mm}$ & $11(40.7 \%)$ \\
& Length $n(\%)$ & $75 \mathrm{~mm}$ & $19(67.9 \%)$ \\
& & $115 \mathrm{~mm}$ & $9(32.1 \%)$ \\
& Diameter $n(\%)$ & $10 \mathrm{~mm}$ & $1(3.6 \%)$ \\
& $12 \mathrm{~mm}$ & $12(42.9 \%)$ \\
& & $14 \mathrm{~mm}$ & $13(46.4 \%)$ \\
& & $16 \mathrm{~mm}$ & $2(7.1 \%)$ \\
\hline
\end{tabular}

Table 5 KSS before and after revision TKA

\begin{tabular}{|c|c|c|}
\hline Preop KSS & Mean (SD) & $72.1(17.3)$ \\
\hline Postop KSS & Mean (SD) & $90.0(13.9)$ \\
\hline $\begin{array}{l}\text { Mean difference: } \\
\text { Postop KSS-Preop KSS }\end{array}$ & $\begin{array}{l}\text { Mean (95\% Cl/P } \\
\text { value) }\end{array}$ & $\begin{array}{l}17.9(8.0-27.8 / P \text { value }< \\
0.001)\end{array}$ \\
\hline Flexion contracture & Preop/postop \% (n) & $23.3 \%(7) / 13.3 \%(4)$ \\
\hline $\begin{array}{l}\text { Unable to flex knee to } \\
90^{\circ}\end{array}$ & Preop/postop \% (n) & $23.3 \%(7) / 3.3 \%(1)$ \\
\hline
\end{tabular}

51.9 and 84.2 months after RTKA. Both late re-revisions were the result of patellar clunk.

\section{Discussion}

This study shows satisfying mid-term clinical and radiographic outcomes of porous-coated metaphyseal sleeves used in RTKA. KSS scores significantly increased, ROMs improved, and the re-revision rate was low.

Bone loss is one of the main challenges that surgeons are faced with during RTKA. Large and uncontained bone defects are traditionally managed with trabecular cones and titanium metaphyseal sleeves. Metaphyseal sleeves offer a long-term fixation to the host bone and create a

Table 6 Radiolucent lines

\begin{tabular}{|c|c|c|c|c|}
\hline & $n$ & $1 \mathrm{~mm}$ & $2 \mathrm{~mm}$ & $3 \mathrm{~mm}$ \\
\hline \multicolumn{5}{|l|}{ Tibial component } \\
\hline \multicolumn{5}{|c|}{ Anterior-posterior view } \\
\hline Medial plateau & 30 & & & \\
\hline Lateral plateau & 30 & 1 & & \\
\hline Medial sleeve & 27 & & 1 & \\
\hline Lateral sleeve & 27 & & 1 & \\
\hline Medial stem & 29 & & 5 & 1 \\
\hline Lateral stem & 29 & 1 & & \\
\hline \multicolumn{5}{|l|}{ Lateral view } \\
\hline Anterior plateau & 30 & 1 & & \\
\hline Posterior plateau & 30 & & & \\
\hline Anterior sleeve & 27 & & 1 & \\
\hline Posterior sleeve & 27 & & & \\
\hline \multicolumn{5}{|l|}{ Femoral component } \\
\hline \multicolumn{5}{|c|}{ Anterior-posterior view } \\
\hline Medial stem & 28 & 1 & 2 & \\
\hline Lateral stem & 28 & 1 & 1 & \\
\hline \multicolumn{5}{|l|}{ Lateral view } \\
\hline Shield & 30 & & 1 & \\
\hline Anterior sleeve & 24 & & 1 & \\
\hline Posterior sleeve & 24 & 2 & & \\
\hline Anterior stem & 28 & 2 & 1 & \\
\hline Posterior stem & 28 & 2 & 1 & \\
\hline
\end{tabular}


Table 7 Complications

\begin{tabular}{lll}
\hline $\boldsymbol{n}$ & $\begin{array}{l}\text { Time from revision } \\
\text { TKA (months) }\end{array}$ & Complication \\
\hline 1 & 0.3 & Drainage of subcutaneous hematoma \\
2 & 0.7 & Tibial-tuberosity avulsion fracture \\
3 & 51.9 & Patellar clunk \\
4 & 84.2 & Patellar clunk \\
\hline
\end{tabular}

TKA total knee arthroplasty

stable platform to receive a femoral or tibial component [20]. As opposed to cones that are bound to the implant through a cement-prosthesis interface, metaphyseal sleeves are attached to the implant through a morse-taper junction, which is thought to remove a source of failure at the cement-implant interface [5, 17]. Furthermore, the added rotational stability in metaphyseal sleeves is thought to offer them an advantage over trabecular cones [21]. Metaphyseal sleeves have reported excellent outcomes in the short-term setting $(<5$ years) [12-14].

Bonanzinga et al. [22]performed a systematic review that included 10 studies that used metaphyseal sleeves. From their results, metaphyseal sleeves demonstrated low septic loosening, a low intraoperative fracture rate and, hence, good-to-excellent clinical outcomes. Their review exemplified the excellent osseointegration of sleeves as the aseptic loosening rate for 1413 sleeves in their study was $0.7 \%$. The authors attributed this excellent rate to the high volume-porosity found in metaphyseal sleeves that facilitates bony ingrowth [22]. The mean follow-up time in their study, however, was only 45 months and, as mentioned by the authors, further studies with a longer follow-up are therefore warranted in order to determine the long-term survivorship and the effectiveness of sleeves.

While there is enough evidence to support the use of metaphyseal sleeves in the short term, to date, very few studies have presented their outcomes for a follow-up of more than 5 years $[15,16]$. It is, therefore, unclear whether these products are as advantageous in the longer term. The purpose of this study was to present our mid-term results for metaphyseal sleeves used in RTKA. To the best of our knowledge, this study presents the longest mean follow-up time in the literature.

The ROM is one of the most significant factors that influences patient satisfaction after TKA [23]. Knee flexion to $90^{\circ}$ and more was impossible in $23.3 \%$ of the cases (7 out of 30 ) before surgery and $3.3 \%$ of the cases (1 out of 30 ) after surgery, demonstrating a markedly improved ROM. Our results moreover demonstrated excellent survivorship of the sleeves as the rate of rerevision during the follow-up period was $13.3 \%$ (4 out of 30 knees). Of the cases in our study that required rerevision, none of them were due to aseptic loosening or bearing failure. This aseptic survival rate of $100 \%$ at a mean of 82.5 months' follow-up time was one of the most notable findings in this study and it reflects the inherent stability of the implants.

Our study presents similar findings to the few midterm studies in the literature that reported good outcomes using metaphyseal sleeves. Fedorka et al. [11] reported a revision rate of $6.8 \%$ (5 out of 74 sleeves) in their study over a median follow-up time of 58.8 months. Two point seven percent ( 2 out of 74 sleeves) required re-operation due to aseptic loosening. In a similar study, Martin-Hernandez et al. [15] reported significant improvements in KSS, Western Ontario and McMaster Universities Osteoarthritis Index (WOMAC), and radiographic assessment over a median follow-up of 71.5 months. Moreover, their study reported no cases of aseptic loosening. In a large cohort study with 104 knees (98 patients, 134 sleeves), Watters et al. [16] reported a metaphyseal sleeve survivorship of $98.5 \%$ over a 5.3 -year follow-up. Their study additionally reported no cases of aseptic loosening.

In a study by Alexander et al. [24] that presented the short-term results of metaphyseal sleeves, end-of-stem pain was described as a significant complication in metaphyseal sleeves and was reported in seven of their cases $(23.3 \%)$. As we did not measure this parameter, this presents a limitation in our study.

While there is currently enough evidence to support the use of using metaphyseal sleeves in the short term [22], their impact on patient outcome is less clear in the longer term. The results of our study in conjunction with the outcomes presented in the literature [11, 15, 16] add evidence to support the use of metaphyseal sleeves in the mid-term setting. Further studies assessing the outcomes of these sleeves over a longer duration are necessary in order to assess the long-term survivorship of these implants.

Our study presents with several limitations. Our study population could have been larger and was, therefore, susceptible to a sampling bias. Despite the fact that our study presents outcomes for the longest mean follow-up time described in the literature, no conclusions can be drawn on the performance of sleeves in the long-term setting ( $>10$ years). Furthermore, as our study lacked a control, it is not possible to definitively support this product over another and future comparative investigations are warranted. Finally, this study's retrospective nature presents an additional limitation.

\section{Conclusion}

Porous-coated metaphyseal sleeves demonstrated excellent rates of survivorship and radiographic ingrowth in the mid-term setting. Further studies are required to 
assess the outcomes of metaphyseal sleeves in the longterm.

\section{Acknowledgements}

Not applicable.

\section{Authors' contributions}

RG: conception, design, analysis, interpretation drafting and revising, and approved the submitted version. SM: acquisition of the data and revising the manuscript, and approved the submitted version. IE: data interpretation and revising the manuscript, and approved the submitted version. IA: design of the study, data interpretation and revising the manuscript, and approved the submitted version. NS: design of the work, data interpretation and revision of the drafted manuscript, and approved the submitted version. AK: data interpretation and revision of the manuscript, and approved the submitted version. AG: data interpretation and revision of the manuscript, and approved the submitted version. YW: design and acquisition of the study, and data, interpretation of the results and revision of the drafted manuscript. He also approved the submitted version.

\section{Funding}

No funding was involved in this study.

\section{Availability of data and materials}

The datasets generated during and/or analyzed during the current study are not publicly available due to the intention of the authors to publish additional studies based on these datasets, but they are available from the corresponding author on reasonable request.

\section{Declarations}

\section{Ethics approval}

This study was approved by the Institutional Ethics Review Board (reference no: 0614-19-TLV).

\section{Consent for publication}

Not applicable

\section{Competing interests}

The authors of this study declare that they have no competing interests.

\section{Author details}

${ }^{1}$ Orthopedic Department, affiliated to the Sackler Faculty of Medicine, Tel Aviv Sourasky Medical Center, Ichilov Hospital, Tel Aviv University, 6 Weizman St, 6423906 Tel Aviv, Israel. ${ }^{2}$ Tel Aviv University, 6423906 Tel Aviv, Israel.

Received: 27 February 2021 Accepted: 20 April 2021

\section{Published online: 04 May 2021}

\section{References}

1. Abdelaal MS, Restrepo C, Sharkey PF (2020) Global perspectives on arthroplasty of hip and knee joints. Orthop Clin North Am 51(2):169-176. https://doi.org/10.1016/j.ocl.2019.11.003

2. Losina E, Thornhill TS, Rome BN, Wright J, Katz JN (2012) The dramatic increase in total knee replacement utilization rates in the United States cannot be fully explained by growth in population size and the obesity epidemic. J Bone Joint Surg Am 94(3):201-207. https://doi.org/10.2106/JBJS. J.01958

3. Kurtz SM, Ong KL, Schmier J, Mowat F, Saleh K, Dybvik E et al (2007) Future clinical and economic impact of revision total hip and knee arthroplasty. J Bone Joint Surg Am 89(Suppl 3):144-151

4. Ponzio DY, Austin MS (2015) Metaphyseal bone loss in revision knee arthroplasty. Curr Rev Musculoskelet Med 8(4):361-367. https://doi.org/10.1 007/s12178-015-9291-x

5. Mancuso F, Beltrame A, Colombo E, Miani E, Bassini F (2017) Management of metaphyseal bone loss in revision knee arthroplasty. Acta Bio-med Atenei Parmensis 88(2S):98-111. https://doi.org/10.23750/abm.v88i2-S.6520

6. Lei P-F, Hu R-Y, Hu Y-H (2019) Bone defects in revision total knee arthroplasty and management. Orthop Surg 11(1):15-24. https://doi.org/1 $0.1111 /$ os. 12425
7. Sandiford NA, Misur P, Garbuz DS, Greidanus NV, Masri BA (2017) No difference between trabecular metal cones and femoral head allografts in revision TKA: minimum 5-year followup. Clin Orthop Relat Res 475(1):118124. https://doi.org/10.1007/s11999-016-4898-9

8. Jensen CL, Winther N, Schrøder HM, Petersen MM (2014) Outcome of revision total knee arthroplasty with the use of trabecular metal cone for reconstruction of severe bone loss at the proximal tibia. Knee 21(6):12331237. https://doi.org/10.1016/j.knee.2014.08.017

9. De Martino I, De Santis V, Sculco PK, D'Apolito R, Assini JB, Gasparini G (2015) Tantalum cones provide durable mid-term fixation in revision TKA. Clin Orthop Relat Res 473(10):3176-3182. https://doi.org/10.1007/s11999-01 5-4338-2

10. Thorsell M, Hedström M, Wick MC, Weiss RJ (2018) Good clinical and radiographic outcome of cementless metal metaphyseal sleeves in total knee arthroplasty. Acta Orthop 89(1):84-88. https://doi.org/10.1080/17453 674.2017.1398013

11. Fedorka CJ, Chen AF, Pagnotto MR, Crossett LS, Klatt BA (2018) Revision total knee arthroplasty with porous-coated metaphyseal sleeves provides radiographic ingrowth and stable fixation. Knee Surg Sports Traumatol Arthrosc 26(5):1500-1505. https://doi.org/10.1007/s00167-017-4493-y

12. Barnett SL, Mayer RR, Gondusky JS, Choi L, Patel JJ, Gorab RS (2014) Use of stepped porous titanium metaphyseal sleeves for tibial defects in revision total knee arthroplasty: short term results. J Arthroplast 29(6):1219-1224. https://doi.org/10.1016/jarth.2013.12.026

13. Bugler KE, Maheshwari R, Ahmed I, Brenkel IJ, Walmsley PJ (2015) Metaphyseal sleeves for revision total knee arthroplasty: good short-term outcomes. J Arthroplast 30(11):1990-1994. https://doi.org/10.1016/j.arth.201 5.05 .015

14. Chalmers BP, Desy NM, Pagnano MW, Trousdale RT, Taunton MJ (2017) Survivorship of metaphyseal sleeves in revision total knee arthroplasty. Arthroplast 32(5):1565-1570. https://doi.org/10.1016/j.arth.2016.12.004

15. Martin-Hernandez C, Floria-Arnal LJ, Muniesa-Herrero MP, EspallargasDoñate T, Blanco-Llorca JA, Guillen-Soriano M, Ranera-Garcia M (2017) Midterm results for metaphyseal sleeves in revision knee surgery. Knee Surg Sports Traumatol, Arthrosc 25(12):3779-3785. https://doi.org/10.1007/s001 67-016-4298-4

16. Watters TS, Martin JR, Levy DL, Yang CC, Kim RH, Dennis DA (2017) Porouscoated metaphyseal sleeves for severe femoral and tibial bone loss in revision TKA. J Arthroplast 32(11):3468-3473. https://doi.org/10.1016/j.arth.2 017.06 .025

17. Scuderi GR, Bourne RB, Noble PC, Benjamin JB, Lonner JH, Scott WN (2012) The New Knee Society Knee Scoring System. Clin Orthop Relat Res 47(1):319. https://doi.org/10.1007/s11999-011-2135-0

18. Engh GA, Ammeen DJ (1999) Bone loss with revision total knee arthroplasty: defect classification and alternatives for reconstruction. Instr Course Lect 48:167-175

19. Ewald FC (1989) The Knee Society total knee arthroplasty roentgenographic evaluation and scoring system. Clin Orthop Relat Res 248:9-12

20. Angerame MR, Jennings JM, Holst DC, Dennis DA (2019) Management of bone defects in revision total knee arthroplasty with use of a stepped, porous-coated metaphyseal sleeve. JBJS Essent Surg Tech 9(2):e14. https:// doi.org/10.2106/JBJS.ST.18.00038

21. Huang R, Barrazueta G, Ong A, Orozco F, Jafari M, Coyle C, Austin M (2014) Revision total knee arthroplasty using metaphyseal sleeves at short-term follow-up. Orthopedics 37(9):e804-e809. https://doi.org/10.3928/01477447-2 0140825-57

22. Bonanzinga T, Akkawi I, Zahar A, Gehrke T, Haasper C, Marcacci M (2019) Are metaphyseal sleeves a viable option to treat bone defect during revision total knee arthroplasty? A Systematic Review. Joints 7(1):19-24. https://doi.org/10.1055/s-0039-1697611

23. Mutsuzaki $H$, Takeuchi $R$, Mataki $Y$, Wadano $Y$ (2017) Target range of motion for rehabilitation after total knee arthroplasty. J Rural Med 12(1):33-37. https://doi.org/10.2185/jrm.2923

24. Alexander GE, Bernasek TL, Crank RL, Haidukewych GJ (2013) Cementless metaphyseal sleeves used for large tibial defects in revision total knee arthroplasty. J Arthroplast 28(4):604-607. https://doi.org/10.1016/j.arth.2012. 08.006

\section{Publisher's Note}

Springer Nature remains neutral with regard to jurisdictional claims in published maps and institutional affiliations. 